\title{
Putative Mechanisms of Drought Tolerance in Maize (Zea mays L.) via Root System Architecture Traits
}

\author{
A. M. M. Al-Naggar ${ }^{1^{*}}$, M. M. Shafik ${ }^{1}$ and M. O. A. Elsheikh ${ }^{2}$ \\ ${ }^{1}$ Department of Agronomy, Faculty of Agriculture, Cairo University, Egypt. \\ ${ }^{2}$ Desert Research Center, Matariya, Cairo, Egypt.
}

\begin{abstract}
Authors' contributions
This work was carried out in collaboration among all authors. Author AMMAN designed the study, wrote the protocol and wrote the first draft of the manuscript. Authors MMS and AMMAN managed the literature searches. Author MOAE managed the experimental process and performed data analyses. All authors read and approved the final manuscript.

Article Information

DOI: 10.9734/ARRB/2019/v32i230079

Editor(s):

(1) Dr. Jin-Zhi Zhang, Key Laboratory of Horticultural Plant Biology (Ministry of Education), College of Horticulture and Forestry Science, Huazhong Agricultural University, China.

(2) Dr. George Perry, Dean and Professor of Biology, University of Texas at San Antonio, USA. Reviewers: (1) Jamile Da Silva Oliveira, Brazilian Agricultural Research Corporation, Brazil.

(2) Dev Nidhi Tiwari, Nepal. (3) Saroj Parajuli, University of Florida, USA. Complete Peer review History: http://www.sdiarticle3.com/review-history/49679
\end{abstract}

Original Research Article

Received 05 April 2019

Accepted 22 June 2019

Published 28 June 2019

\begin{abstract}
Identifying maize genotypes with favorable root architecture traits for drought tolerance is prerequisite for initiating a successful breeding program for developing high yielding and drought tolerant varieties of maize. The aims of the present study were: (i) to identify drought tolerant genotypes of maize at flowering and grain filling, (ii) to interpret the correlations between the drought tolerance and root architecture traits and (iii) to identify the putative mechanisms of drought tolerance via root system traits. An experiment was carried out in two years using a split plot design with three replications. The main plots were assigned to three water stress levels, namely: well watering (WW), water stress at flowering (WSF) and water stress at grain filling (WSG), and subplots to 22 maize cultivars and populations. Drought tolerance index (DTI) had strong and positive associations with crown root length $(C R L)$, root circumference $(R C)$ and root dry weight (DRW) under both WSF and WSG, a negative correlation with brace root whorls (BW), and positive correlations with crown root number $(\mathrm{CN})$ under WSF and brace root branching $(\mathrm{BB})$ and crown root
\end{abstract}


branching (CB) under WSG. These root traits are therefore considered as putative mechanisms of drought tolerance. The cultivars Pioneer-3444, SC-128, Egaseed-77, SC-10 and TWC-324 showed the most drought tolerant and the highest yielding in a descending order; each had a number of such drought tolerance mechanisms. Further investigation should be conducted to determine the underlying root mechanisms contributing to the selection of water-efficient hybrids of maize.

Keywords: Corn; crown and brace roots; correlations; drought tolerance index.

\section{INTRODUCTION}

Maize (Zea mays L.) in Egypt is mainly used for poultry industry and animal feed. For acreage and production, it ranks second to wheat among cereal crops in Egypt. It is grown as a summer season crop and well irrigated by water coming from Nile River and its branches and canals. Current maize hybrids cultivated in Egypt are selected under well irrigation and therefore are subject to yield losses when grown under water deficit. The irrigation water is reducing, especially at the ends of canals and due to expanding maize cultivation into the deserts, where sandy soils are of low water holding capacity. In order to stabilize maize production in Egypt, there is a need to develop drought tolerant maize hybrids.

Maize is very sensitive to drought during the flowering and grain-filling periods [1]. However, Witt et al. [2] reported that "most of yield production happened approximately in the period from two weeks before flowering time until two weeks after flowering time". Developing maize varieties that are tolerant to drought is, therefore considered critical for increasing the maize production. Several investigations have been undertaken across the years to improve drought tolerance in breeding programs. Edmeades et al. [3] reported that germplasm developed from drought tolerant source populations performed significantly better under drought stress compared to conventional populations.

Root system traits are very important for productivity of plants under water stress [4]. "Plants avoid drought by increasing their water uptake from the soil and their adaptation to the physical and chemical soil problems, via their root system plasticity" [5]. The importance of steep and strong roots for achieving high yield in maize under water stress has been reported by Hund et al. [6]. Rauf and Sadaqat [7] stated that "drought tolerant genotypes generally increase the photosynthates allocation for root elongation under drought stress". Rauf et al. [8] reported that genetic variation for root elongation has been shown in maize. The effects of root architecture and size on maize yield also depend on the soil water distribution and the competition for water among the plants [9].

Trait interrelationships in particular determine the degree of association among traits and how they may increase selection efficiency. It is useful if indirect selection for root traits gives greater response to selection for grain yield trait than direct selection for the same trait. The main criterion for drought tolerance selection is the association of each root trait with grain yield under stress conditions $[9,10]$.

To start a successful breeding program for improving drought tolerance, available maize germplasm should be screened for related traits to drought tolerance; e.g. root architecture traits under deficit irrigation to identify the best ones for further use in extracting the best parental inbred lines for developing drought tolerant hybrids. The aims of the present study were: (i) to characterize 22 maize genotypes for their root system architecture traits and their drought tolerance in order to identify drought tolerant ones, (ii) to interpret the correlations between the drought tolerance and root traits and (iii) to identify the putative mechanisms of drought tolerance via root system architecture.

\section{MATERIALS AND METHODS}

This experiment was conducted in 2016 and 2017 maize growing seasons at the Agric. Exper. and Res. Sta. of the Fac. of Agric., Cairo University, Giza, Egypt located at $30^{\circ} 02^{\prime} \mathrm{N}$ latitude and $31^{\circ} 13^{\prime} \mathrm{E}$ longitude with an altitude of $22.50 \mathrm{~m}$ asl.

\subsection{Plant Materials}

The plant material of this study consisted of twenty two maize genotypes (Zea mays L.), i.e. 15 Egyptian cultivars (ten single crosses and five 
3-way crosses) and seven populations (Table 1). These materials were kindly provided by Hi-Tec Company (HT-2031, HT-2066, HT-1100), DuPont Pioneer Company (P-30K09, P-3444, P32D99), Fine Seeds Company (F-1005), Egaseed Company (Ega-77), Wataniya Company (W-11) and Agricultural Research Center-Egypt (the rest of genotypes). The studied genotypes represent the available germplasm in Egypt and some of them could be considered sources for extracting drought tolerant inbred lines.

\subsection{The Experimental Procedures}

The planting date was April $24^{\text {th }}$ and April $30^{\text {ht }}$ in 2016 and 2017 seasons, respectively. Sowing was done in rows; each row was $4 \mathrm{~m}$ long and 70 $\mathrm{cm}$ width. Seeds were over sown in hills $25 \mathrm{~cm}$ apart, thereafter (after 21 days from planting and before the first irrigation) were thinned to one plant/hill to achieve a plant density of 57,120 plants/ha. Each experimental plot included two rows $\left(\right.$ plot size $=5.6 \mathrm{~m}^{2}$ ).

\subsection{The Experimental Design}

The experiment was conducted using a split-plot design in randomized complete blocks arrangement with three replications. The main plots were assigned to three watering systems, i.e. well watering, water stress at flowering and water stress at grain filling. Each main plot was surrounded with a border of $4 \mathrm{~m}$ width, to avoid water interference from main plot to another. The sub plots were allotted to twenty-two maize genotypes.

\subsection{Watering Systems}

1. Well watering (WW): The flood irrigation was used; the second irrigation was applied after 21 days from sowing and subsequent irrigations were given at 12 days intervals.

2. Water stress at flowering stage (WSF): The irrigation was just like well watering, but the $4^{\text {th }}$ and $5^{\text {th }}$ irrigations were prevented, resulting in 24 days drought stress just before and during flowering stage.

3. Water stress at grain filling stage (WSG): The irrigation was just like well watering, but the $6^{\text {th }}$ and $7^{\text {th }}$ irrigations were prevented, resulting in 24 days drought stress during the grain filling stage.

\subsection{Other Agricultural Practices}

All other agricultural practices were followed according to the recommendations of ARC, Egypt. Triple Superphosphate $\left(46 \% \mathrm{P}_{2} \mathrm{O}_{5}\right)$ at the rate of $70 \mathrm{~kg} \mathrm{P}_{2} \mathrm{O}_{5} /$ ha was added to soil before sowing during soil preparation for planting. Urea $(46 \% \mathrm{~N})$ at the rate of $285 \mathrm{~kg} \mathrm{~N} / \mathrm{ha}$ was applied in two equal doses before the second and third irrigations. Weed control was done chemically with Stomp herbicide just after sowing and before the planting irrigation and manually by hoeing twice, the first before the second irrigation and the second before the third irrigation. Pest control was done when required by spraying plants with Lannate (Methomyl) 90\% (manufactured by DuPont, USA) against corn borers.

\subsection{Soil Analysis}

Soil analyses of the experimental site was done at the Laboratories of Soil and Water Research Institute of ARC, Egypt. Across the two seasons, soil type was clay loam: Silt $(36.4 \%)$, clay $(35.3 \%)$, fine sand $(22.8 \%)$ and coarse sand (5.5\%), pH (7.92), EC (1.66 dSm ${ }^{-1}$ ), SP (62.5), $\mathrm{CaCO}_{3}(7.7 \%)$, Soil bulk density $\left(1.2 \mathrm{~g} \mathrm{~cm}^{-3}\right)$, $\mathrm{HCO}_{3}(0.71 \mathrm{mEqu} / \mathrm{l}), \mathrm{Cl}(13.37 \mathrm{mEqu} / \mathrm{l}), \mathrm{SO}_{4}$ (0.92mEqu/l), $\mathrm{Ca}^{++} \quad(4.7 \mathrm{mEqu} / \mathrm{l}), \quad \mathrm{Mg}^{++}$ (2.2mEqu/l), $\mathrm{Na}^{+}(8.0 \mathrm{mEqu} / \mathrm{l}), \mathrm{K}^{+}(0.1 \mathrm{mEqu} / \mathrm{l}), \mathrm{N}$, $\mathrm{P}, \mathrm{K}, \mathrm{Zn}, \mathrm{Mn}$ and Fe $(371,0.4,398,4.34,9.08$ and $10.14 \mathrm{mg} / \mathrm{kg}$, respectively).

\subsection{Data Recorded}

1. Grain yield/plant (GYPP) (g) was estimated from a sample of ten guarded plants/plot (adjusted at $15.5 \%$ grain moisture).

2. Grain yield/ha (GYPH) (ton) was estimated by adjusting grain yield/plot at $15.5 \%$ grain moisture to grain yield/ha.

\subsection{Root Traits}

At the end of each water stress treatment (80 and 100 days from emergence for WSF and WSG, respectively) and just after irrigation, roots of three plants from each experimental plot were excavated by removing a soil cylinder of $40 \mathrm{~cm}$ diameter and a depth of $40 \mathrm{~cm}$ with plant base as the horizontal centre of the soil cylinder. Excavation was carried out using standard shovels. The excavated root crowns were shaken briefly to remove a large fraction of the soil adhering to the root crown. Most of the remaining soil was then removed by soaking the 
root crown in running water. In a third step, remaining soil particles were removed from the root crown by vigorous rinsing at low pressure. The clean roots were measured or visually scored (Fig. 1) for the following traits:

3. Number of above-ground whorls occupied with brace roots (BW).

4. Number of brace roots (BN).

5. Angle of $1^{\text {st }}$ arm of the brace roots originating from whorl 1 (BA) (score).

6. Branching density of brace roots (BB) (score).

7. Number of crown roots (CN) (score).

8. Crown roots angle (CA) (score).

9. Branching density of crown roots (CB) (score).

Traits from No. 5 to No. 9 were assigned values from one to nine according to Trachsel et al. [10], where one indicates shallow root angles $\left(10^{\circ}\right)$, low root numbers and a low branching density and nine indicates steep root angles $\left(90^{\circ}\right)$, high numbers and a high branching density (Fig. 1).

10. Crown root length $(C R L)(\mathrm{cm})$. The root length, measured as the distance between the last node to the end tip of the root.
11. Root circumference $(R C)(\mathrm{cm})$. RC was measured from maximum root system width.

12. Root (crown and brace) dry weight (RDW) (g). The measured root was first spread out in the sun for partial drying and then put in an oven for total drying at $40^{\circ} \mathrm{C}$ for 24 hours. After drying the roots were weighed using an electronic scale.

\subsection{Drought Tolerance Index (DTI)}

Drought tolerance index is the factor used to differentiate between the genotypes from tolerance point of view and it is calculated by the equation of Fageria [11] as follows:

$$
\mathrm{DTI}=(\mathrm{Y} 1 / \mathrm{AY} 1) \mathrm{X}(\mathrm{Y} 2 / \mathrm{AY} 2)
$$

Where, $\mathrm{Y} 1$ = trait mean of a genotype at well watering. $A Y 1=$ average trait of all genotypes at well watering. $Y 2=$ trait mean of a genotype at water stress. AY2 = average trait of all genotypes at water stress. When DTI is $\geq 1$, it indicates that genotype is tolerant $(T)$ to drought. If $\mathrm{DTI}$ is $<1$, it indicates that genotype is sensitive (S) to drought.

Table 1. Name, origin, genetic nature and grain color of studied maize genotypes

\begin{tabular}{|c|c|c|c|c|}
\hline $\begin{array}{l}\text { Genotype } \\
\text { No. }\end{array}$ & Name & Origin & $\begin{array}{l}\text { Genetic } \\
\text { nature }\end{array}$ & $\begin{array}{l}\text { Grain } \\
\text { colour }\end{array}$ \\
\hline 1 & HT-2031 & Hi-Tec Co., Egypt & $\mathrm{SC}$ & $\mathrm{W}$ \\
\hline 2 & P-30K09 & DuPont Pioneer Co. & SC & W \\
\hline 3 & $F-1005$ & Fine Seeds Co., Egypt & SC & W \\
\hline 4 & Ega-77 & Egaseed Co., Egypt & SC & W \\
\hline 5 & SC-10 & ARC, Egypt & SC & W \\
\hline 6 & SC-128 & ARC, Egypt & SC & W \\
\hline 7 & HT-2066 & Hi-Tec Co., Egypt & sc & Y \\
\hline 8 & P-3444 & DuPont Pioneer Co. & SC & $\mathrm{Y}$ \\
\hline 9 & SC-166 & ARC, Egypt & SC & $\mathrm{Y}$ \\
\hline 10 & P-32D99 & DuPont Pioneer Co. & SC & Y \\
\hline 11 & HT-1100 & Hi-Tec Co., Egypt & TWC & W \\
\hline 12 & W-11 & Watania Co., Egypt & TWC & W \\
\hline 13 & TWC-324 & ARC, Egypt & TWC & W \\
\hline 14 & TWC-360 & ARC, Egypt & TWC & $\mathrm{Y}$ \\
\hline 15 & TWC-352 & ARC, Egypt & TWC & $\mathrm{Y}$ \\
\hline 16 & Giza Baladi & ARC, Egypt & Pop & W \\
\hline 17 & Pop-45 & ARC, Egypt & Pop & $\mathrm{Y}$ \\
\hline 18 & Nubaria & ARC, Egypt & Pop & Y \\
\hline 19 & Nebraska Midland & USA & Pop & $\mathrm{Y}$ \\
\hline 20 & Midland Cunningham & Eldorado,Kansas, USA & Pop & $\mathrm{Y}$ \\
\hline 21 & Golden Republic & Beltsville,Kansas, USA & Pop & $\mathrm{Y}$ \\
\hline 22 & Sweepstakes 5303 & USA & Pop & Y \\
\hline
\end{tabular}

$A R C=$ Agricultural Research Center, $S C=$ Single cross, $T W C=$ Three-way cross, $P$ op $=$ Population, $W=W h i t e$, $Y=Y e l l o w$ 


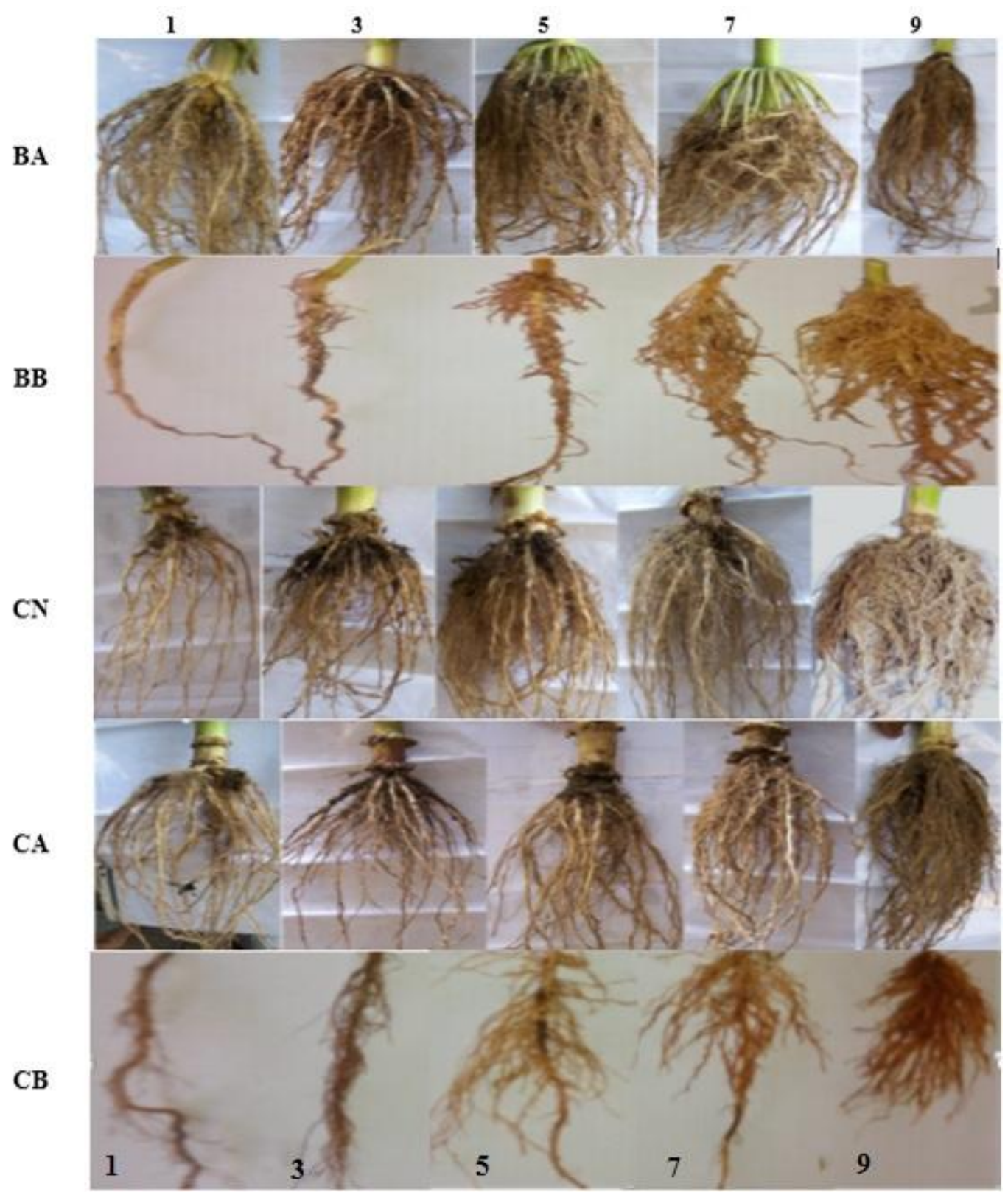

Fig. 1. Images of brace roots angle (BA), brace roots branching density (BB), crown roots number $(\mathrm{CN})$, crown roots angle (CA) and crown roots branching (CB) displayed were scored with 1, 3, 5, 7 and 9

\subsection{Statistical Analyses}

Analysis of variance of the split plot design was performed on the basis of individual plot observation using the MIXED procedure of MSTAT ${ }^{\circledR}$. Combined analysis of variance across the two growing seasons was also performed if the homogeneity test was non-significant. Moreover, combined analysis for each environment separately across seasons was performed as randomized complete blocks design. Least significant difference (LSD) values were calculated to test the significance of differences between means according to Steel et al. [12].

Simple correlation coefficients were calculated between pairs of studied traits under well watering 
(WW), water stress (WS), severe water stress (SWS) and combined across all irrigation treatments according to Singh and Narayanan [13]. Spearman's rank correlation coefficients calculated among studied root traits and other studied traits under studied environments. It was computed by using SPSS 17 computer software and the significance of the rank correlation coefficient was tested according to Steel et al. [12].

\section{RESULTS AND DISCUSSION}

\subsection{Analysis of Variance}

Combined analysis of variance across seasons of the split plot design (Table 2) indicated that mean squares due to season were significant $(P \leq 0.05$ or $P \leq 0.01)$ for BW, BA, CA, CB, GYPP and GYPH traits. Mean squares due to irrigation regime were significant $(P \leq 0.05$ or $P \leq 0.01)$ for six traits, namely CN, CB, RC, RDW, GYPP and GYPH. Mean squares due to genotype were significant $(P \leq 0.01)$ for all 12 studied root traits and grain yield.

Mean squares due to the $1^{\text {st }}$ order interaction were significant $(P \leq 0.05$ or 0.01$)$ for four traits (BN, RC, RDW and GYPH) due to $1 \times S$, for six traits (BB, CN, CB, RDW, GYPP and GYPH) due to $\mathrm{G} \times \mathrm{S}$ and two traits (GYPP and $\mathrm{GYPH}$ ) due to $\mathrm{G} \times \mathrm{I}$. Mean squares due to the $2^{\text {nd }}$ order interaction, i.e. $\mathrm{G} \times \mathrm{S} \times \mathrm{I}$, were significant $(\mathrm{P} \leq$ 0.01) for three traits, namely BB, GYPP and GYPH (Table 2).

Root system traits are very important for productivity of plants under water stress conditions [4]. In order to improve maize yield, breeders should select genotypes with a root system adapted to the water stress conditions of the target environment. Results of the present study indicated that irrigation regime had a significant effect on six traits (CN, CB, RC, RDW, GYPP and GYPH). Most importantly, genotype had an obvious effect on all studied root traits and grain yield. The role of maize genotype is in agreement with the findings of Trachsel et al. [10] for maize root system architecture traits and AlNaggar et al. [14,15] for grain yield. Mean squares due to the the $1^{\text {st }}$ and $2^{\text {nd }}$ order interactions were significant for some root and yield traits, indicating that for such traits, the rank of maize genotypes differ from irrigation treatment to another, and from one season to another and the possibility of selection for improved root traits and grain yield under a specific drought stressed environment as suggested by Al-Naggar et al. [16-20]. Combined analysis of variance of RCBD under each environment (data not presented) indicated the significance of differences among studied genotypes for the majority of studied root traits and grain yield under each irrigation treatment.

Table 2. Combined analysis of variance across 2016 and 2017 seasons for studied root traits of 22 maize genotypes under four irrigation regimes

\begin{tabular}{|c|c|c|c|c|c|c|}
\hline \multirow[t]{2}{*}{ SOV } & \multicolumn{6}{|c|}{ Mean squares } \\
\hline & BW & BN & BA & BB & $\mathrm{CN}$ & CA \\
\hline Season (S) & * & ns & ** & ns & ns & ** \\
\hline Irrigation regime(I) & ns & ** & ns & ns & * & ns \\
\hline $1 \times S$ & * & ns & ns & ns & ns & ns \\
\hline Genotype (G) & ** & $* *$ & $* *$ & ** & ** & $* *$ \\
\hline$G \times S$ & ns & ns & ns & ** & * & ns \\
\hline $\mathrm{G} \times \mathrm{I}$ & ns & ns & ns & ns & ns & ns \\
\hline \multirow[t]{2}{*}{$\mathrm{G} \times \mathrm{S} \times \mathrm{I}$} & ns & ns & ns & * & ns & ns \\
\hline & CB & CRL & RC & RDW & GYPP & GYPH \\
\hline Season (S) & ** & ns & $\mathrm{ns}$ & $\mathrm{ns}$ & * & $* *$ \\
\hline Irrigation regime(I) & ** & ns & $* *$ & ** & ** & ** \\
\hline $1 \times S$ & ns & ns & * & ** & ns & ** \\
\hline Genotype (G) & $* *$ & $* *$ & ** & ** & $* *$ & ** \\
\hline $\mathrm{G} \times \mathrm{S}$ & ** & ns & ns & ** & ** & ** \\
\hline $\mathrm{G} \times \mathrm{I}$ & ns & ns & ns & ns & ** & ** \\
\hline$G \times S \times I$ & ns & ns & $\mathrm{ns}$ & ns & $* *$ & ** \\
\hline
\end{tabular}

$B W=$ Number of above-ground whorls occupied with brace roots, $B N=$ Number of brace roots, $B A=B r a c e$ root angle, $B B=$ Branching density of brace roots, $C N=$ Number of crown roots, $C A=$ Crown roots angle,

$C B=$ Branching density of crown roots, $C R L=$ Crown root length, $R C=$ Root circumference, $R D W=$ Roots dry weight, GYPP = Grain yield/plant, GYPH= grain yield/ha, ns= not significant, * and ** indicate significance at 0.05 and 0.01 probability levels, respectively 


\subsection{The Effect of Genotype}

Means and lowest and highest values (Ranges) of all studied traits across all genotypes, all watering treatments and across two seasons are presented in Table (3). Genotypes ranged for grain yield/ha from 13.03 ton/ha (genotype No.8; $\mathrm{P}-3444$ ) to 2.69 ton/ha (genotype No. 22; Sweepstakes 5303), grain yield/plant from 158.5 g (genotype No. 6; SC 128) to 62.5 g (genotype No. 22; Sweepstakes 5303), number of aboveground whorls occupied with brace roots from 3.0 from (genotype No. 17) to 1.9 (genotype No. 8), number of brace roots from 49.0 (genotype No. 10 ) to 25.6 (genotype No. 21), angle of $1^{\text {st }}$ arm of the brace roots originating from whorl 1 from 7.7 (genotype No. 19) to 5.5 (genotype No. 1), branching density of brace roots from 6.2 (genotype No. 9) to 3.4 (genotype No. 18), number of crown roots from 4.5 (genotype No. 6) to 1.9 (genotype No. 21), crown roots angle from 8.1 (genotype No. 10) to 5.6 (genotype No. 7 ), branching density of crown roots from 6.5 (genotype No. 8) to 3.0 (genotype No. 21), crown root length from $26.1 \mathrm{~cm}$ (genotype No. 5) to $20.4 \mathrm{~cm}$ (genotype No. 18), root circumference from $38.1 \mathrm{~cm}$ (genotype No. 7) to $25.9 \mathrm{~cm}$ (genotype No. 21) and roots dry weight from $36.8 \mathrm{~g}$ (genotype No. 8) to $11.2 \mathrm{~g}$ (genotype No. 20).

The single cross cultivar Pioneer-3444 developed by DuPont Pioneer Co. exhibited the highest mean values for four traits [grain yield/ha (GYPH), root circumference (RC), crown root branching (CB) and roots dry weight (RDW)] and second highest for GYPP, brace root branching $(\mathrm{BB})$, number of crown roots $(\mathrm{CN})$, crown root length (CRL), i.e. most important yield and root traits. The genotype SC-128 developed by ARCEgypt was the highest in GYPP and number of crown roots and second highest in crown root branching. The genotype Ega-77 developed by Egaseed Co., Egypt showed the third highest in grain yield and the highest in brace root angle (BA). The genotype SC-10 developed by ARC-Egypt showed the highest means for one trait (crown root length; $\mathrm{CRL}$ ); it gave the fourth highest grain yield per plant and per hectare.

On the contrary, the genotype Pop. Sweepstakes 5303 exhibited the lowest means for two traits, namely GYPP, GYPH. The genotype Pop. Golden Republic exhibited the lowest means for two traits, namely $\mathrm{BN}$ and $\mathrm{CN}$. The genotype Pop. Nubaria showed the lowest means for two traits (BB and CRL).

Means of the 22 maize genotypes showed wide ranges of performance (difference between minimum and maximum values) for all studied root and yield traits across all irrigation treatments. Three commercial varieties showing the highest grain yield showed also the highest means for a number of root traits. The superiority of these three commercial varieties in six root traits (RC, CB, RDW, BB, CN and CRL) for Pioneer-3444, two traits ( $\mathrm{CN}$ and $\mathrm{CB}$ ) for SC128, one trait (BA) for Egaseed 77 and one trait (CRL) for SC-10 might be the reason of their superiority in grain yield, because good roots may help the plants to uptake more water and nutrients from the soil for their biological activities, especially under drought conditions $[4,21,22]$.

Table 3. Mean, lowest and highest values of all studied traits across two seasons and across all watering treatments

\begin{tabular}{llllll}
\hline Trait & Unit & Mean & Lowest & Highest & LSD $_{.05}$ \\
\hline Brace root whorls number & No. & 2.5 & $1.9(8)$ & $3.0(10,11,17)$ & 0.36 \\
Brace roots number & No. & 37.1 & $25.6(21)$ & $49.0(10)$ & 6.8 \\
Brace roots angle & score & 6.7 & $5.5(1)$ & $7.7(19)$ & 0.74 \\
Brace roots branching & score & 4.9 & $3.4(18)$ & $6.2(9)$ & 1.09 \\
Crown roots number & score & 3.2 & $1.9(21)$ & $4.5(6)$ & 0.86 \\
Crown roots angle & score & 6.7 & $5.6(7)$ & $8.1(10)$ & 0.76 \\
Crown roots branching & score & 4.2 & $3.0(21)$ & $6.5(8)$ & 0.91 \\
Crown roots length & $\mathrm{cm}$ & 22.8 & $20.4(18)$ & $26.1(5)$ & 2.57 \\
Root circumference & $\mathrm{cm}$ & 32.7 & $25.9(21)$ & $38.1(8)$ & 2.85 \\
Roots dry weight & $\mathrm{g}$ & 22.3 & $11.2(20)$ & $36.8(8)$ & 6.05 \\
Grain yield/plant & $\mathrm{g}$ & 107.3 & $62.5(22)$ & $158.5(6)$ & 9.72 \\
grain yield/ha & ton & 7.18 & $2.69(22)$ & $13.03(8)$ & 0.39 \\
\hline
\end{tabular}

Lowest and highest values are followed by genotype No. mentioned in Table 1 (Between brackets) 
In general, the commercial varieties P-3444, SC128, Egaseed-77 and SC-10 were the best genotypes in our experiment; they showed the highest grain yield and the best root architectural traits across all studied irrigation treatments; they could be recommended for farmers use under a range of different environments as well as for maize breeding programs. On the contrary, it is observed that most of root and yield traits with undesirable mean values were exhibited by populations and the vice versa for traits with desirable means, which were mostly shown by the single crosses.

\subsection{Genotype $\times$ Water Stress Interaction}

For root traits (Table 4), data were measured under WWF, WWG, WSF and WSG. Under WWF, WWG, WSF and WSG, for BW the lowest mean was exhibited by genotypes No. 2, 13, 17 and 21 and the highest mean was shown by genotypes No. 17, 19, 4 and 10, for BN the lowest mean by genotypes No. 21, 12, 4 and 21 and the highest mean by genotypes No. 11, 11, 10 and 10 , for BA the lowest by genotypes No. $1,9,14$ and 1 and the highest mean was shown by genotypes No. 19, 21, 21 and 19, for BB the lowest by genotypes No. 18, 18, 13 and 20 and the highest mean was shown by genotypes No. $5,15,6$ and 9 , for $\mathrm{CN}$ the lowest by genotypes No. $18,19,13$ and 13 and the highest mean was shown by genotypes No. 12, 8, 6 and 3, for CA the lowest by genotypes No. 2, 5, 7 and 1 and the highest mean was shown by genotypes No. 10, 10, 21 and 10, for $C B$ the lowest by genotypes No. 21, 17, 19 and 19 and the highest by genotypes No. 8, 8, 6 and 8 , for CRL the lowest by genotypes No. 14, 18, 22 and 22 and the highest mean by genotypes No. 8, 5, 9 and 4, for RC the lowest by genotypes No. 18, 19, 19 and 21 and the highest by genotypes No. 7, 8, 7 and 8 and for RDW the lowest by genotypes No. $20,18,19$ and 21 and the highest by genotypes No. $8,8,5$ and 8 , respectively.

For grain yield (Tables 5 and 6), data were measured under WW, WSF and WSG. The lowest mean GYPP was shown by genotypes No. 19, 22 and 15 and the highest by genotypes No. 1, 6 and 8 under WW, WSF and WSG, respectively. For GYPH, the lowest mean was exhibited by Genotypes No. 22, 22 and 22 and the highest mean was shown by Genotypes No. 8,4 and 8 under WW, WSF and WSG, respectively.

On the contrary, the worst genotypes were No. 22 (Sweepstakes) in 3 traits (GYPP, GYPH,
CRL) under WSG, 3 traits (GYPP, GYPH, CRL) under WSF and one trait (GYPH) under WW, the genotype No. 21 (Golden Republic) in 4 traits (BW, BN, RC, RDW) under WSG, two traits $(B N, C B)$ under WWF, the genotype No. 19 (Nebraska) in one trait (CB) under WSG, and 3 traits (CB, RC, RDW) under WWG and the genotype No. 18 (Nubaria) in two traits (CN, RC) under WWG and one trait (GYPP) under WW.

The four highest and the four lowest performing genotypes under water stress at flowering (WSF) and grain filling (WSG) across seasons are presented in Table 6 . Under WSF conditions, the highest mean grain yield/ha was achieved by the single cross Egaseed-77 (developed by Egaseed Co.), followed by P-3444 (developed by Pioneer Co.), SC 128 (developed by ARC, Egypt) and HT-2066 (developed by $\mathrm{Hi}$ Tec Co.) in a descending order. The single cross Egaseed-77 was amongst the four highest genotypes under WSF for GYPH, GYPP, BA and CRL. The single cross P-3444 was amongst the four highest genotypes under WSF for GYPH, GYPP, CN, CB and CRL. The single cross SC-128 was amongst the four highest genotypes under WSF for GYPH, GYPP, BB, CN, CB, RC, and RDW. The single cross HT-2066 was amongst the four highest genotypes under WSF for GYPH, GYPP, $\mathrm{CN}$ and RC.

Under WSG conditions, the highest mean grain yield/ha was achieved by the single cross P-3444 (developed by Pioneer) followed by SC-128 (developed by ARC), TWC-324 (developed by ARC) and SC-166 (developed by ARC) in a descending order. The single cross P-3444 was amongst the four highest genotypes in GYPH, GYPP, BB, CB, CRL, RC and RDW, i.e. most important grain yield and root architecture traits. The single cross SC-128 was amongst the four highest genotypes in GYPH, GYPP, BB, CN, CB and RDW (the most important grain yield and root architecture traits). The single cross SC-166 was amongst the four highest genotypes in GYPH and BB.

Results from Tables (4 and 5) concluded that the best genotypes were No. 8 (P-3444) in 5 traits (GYPP, GYPH, CB, RC, RDW) under WSG, 4 traits (CN, CB, RC, RDW) under WWG, 3 traits (CA, CRL, RDW) under WWF and one trait (GYPH) under WW, the genotype No. 6 (SC 128) in 4 traits (GYPP, BB, CA, CB) under WSF, the genotype No.5 (SC 10) in two traits (BB and CRL) under WWF and WWG, respectively, the genotype No. 7 (Hi-Tec 2066) in one trait (RC) under WSF and RC under WWF, the genotype 
No. 4 (Egaseed 77) in one trait (GYPH) under WSF, and the genotype No. 2 (30K09) in one trait (GYPH) under WSF.

The best genotypes in grain yield under drought at either flowering or grain filling were characterized by one or more desirable root architecture traits. Accumulating genes of more desirable root characteristics in one genotype might help plants to search water and nutrients in the soil and consequently help plant to accomplish its biological activities and achieve almost its potential grain yield under drought stress at flowering or grain filling stages $[4,10$,
21-24]. The studied single-cross hybrids P-3444, Egaseed-77 and SC-128 were considered drought tolerant genotypes under drought stress at flowering and/or grain filling stages and would be offered to future breeding programs to utilize their genes of desirable root architecture and grain yield traits in improving maize drought tolerance under Egyptian conditions. It should be mentioned that the hybrid P-3444 was characterized in this experiment by its ability to stay green even under water stress, which might help it to tolerate water stress at grain filling stage in a way much better than other tested hybrids and populations.

Table 4. Mean, lowest and highest values of all studied traits across two seasons under each irrigation treatment

\begin{tabular}{|c|c|c|c|c|c|c|c|c|}
\hline \multirow[t]{2}{*}{ Watering } & Mean & Lowest & Highest & LSD. $_{05}$ & Mean & Lowest & Highest & LSD. .05 \\
\hline & \multicolumn{4}{|c|}{ Brace root whorls no. } & \multicolumn{4}{|c|}{ Brace roots no. } \\
\hline WWF & 2.52 & $2(2)$ & $3.1(17)$ & 0.7 & 39 & $27.3(21)$ & $47(11)$ & 16.58 \\
\hline WWG & 2.48 & $1.66(13)$ & $3.33(19)$ & 0.81 & 37.1 & $22.7(12)$ & $54.7(11)$ & 14.5 \\
\hline WSF & 2.29 & $1.8(17)$ & $2.9(4)$ & 0.57 & 31.5 & $23(4)$ & $43.3(10)$ & 7.3 \\
\hline \multirow[t]{2}{*}{ WSG } & 2.64 & $1.5(21)$ & $3.3(10)$ & 0.81 & 40.8 & $25.2(21)$ & $59(10)$ & 14.76 \\
\hline & \multicolumn{4}{|c|}{ Brace root angle (Score) } & \multicolumn{4}{|c|}{ Brace root branching (Score) } \\
\hline WWF & 6.7 & $5(1)$ & $8.3(19)$ & 1.62 & 5.3 & $3.3(18)$ & $7(5)$ & 2.38 \\
\hline WWG & 6.7 & $5(9)$ & $7.3(21)$ & 1.88 & 4.7 & $2(18)$ & $7(15)$ & 2.66 \\
\hline WSF & 6.9 & $5.8(14)$ & $7.5(21)$ & 1.02 & 4.9 & $3(13)$ & $6.8(6)$ & 1.66 \\
\hline \multirow[t]{2}{*}{ WSG } & 6.5 & $4.7(1)$ & $7.5(19)$ & 1.25 & 4.7 & $2.3(20)$ & $6.2(9)$ & 2.02 \\
\hline & \multicolumn{4}{|c|}{ Crown root number (Score) } & \multicolumn{4}{|c|}{ Crown root angle (Score) } \\
\hline WWF & 3.82 & $1.7(18)$ & $6(12)$ & 2.2 & 6.8 & $5.7(2)$ & $8(10)$ & 1.6 \\
\hline WWG & 2.66 & $1(19)$ & $4(8)$ & 1.8 & 6.5 & $5.3(5)$ & $8(10)$ & 1.92 \\
\hline WSF & 3.38 & $1.8(13)$ & $5.3(6)$ & 1.3 & 6.9 & $5(7)$ & $8(21)$ & 1.2 \\
\hline \multirow[t]{2}{*}{ WSG } & 3.05 & $1.8(13)$ & $5(3)$ & 1.47 & 6.5 & $5.2(1)$ & $8.5(10)$ & 1.25 \\
\hline & \multicolumn{4}{|c|}{ Crown root branching (Score) } & \multicolumn{4}{|c|}{ Crown root length $(\mathrm{cm})$} \\
\hline WWF & 4.6 & $3(2)$ & $6(8)$ & 1.95 & 22.4 & $18.6(14)$ & $25.9(8)$ & 6.67 \\
\hline WWG & 4.1 & $2(17)$ & $7.3(8)$ & 2.35 & 23.2 & $18.8(18)$ & $28.1(5)$ & 5.1 \\
\hline WSF & 4.6 & $3.2(19)$ & $6.3(6)$ & 1.49 & 23.9 & $21.2(22)$ & $26.2(9)$ & 4.1 \\
\hline \multirow[t]{2}{*}{ WSG } & 3.7 & $2.2(19)$ & $6.5(8)$ & 1.54 & 21.76 & $16.9(22)$ & $26(4)$ & 4.4 \\
\hline & \multicolumn{4}{|c|}{ Root circumference (cm) } & \multicolumn{4}{|c|}{ Root dry weight (g) } \\
\hline WWF & 34.7 & $28.1(18)$ & $40.4(7)$ & 6.48 & 26.2 & $8.2(20)$ & $40.7(8)$ & 14.36 \\
\hline WWG & 30.7 & $23.3(19)$ & $41(8)$ & 6.5 & 21 & $8.2(18)$ & $44.9(8)$ & 12.96 \\
\hline WSF & 34.4 & $26.5(19)$ & $42.5(7)$ & 4.97 & 18.8 & $9.8(19)$ & $33.6(5)$ & 9.53 \\
\hline \multirow[t]{2}{*}{ WSG } & 30.9 & $23.3(21)$ & $36.6(8)$ & 4.95 & 23.3 & $9.9(21)$ & $40.1(8)$ & 11.53 \\
\hline & \multicolumn{4}{|c|}{ Grain yield/plant $(\mathrm{g})$} & \multicolumn{4}{|c|}{ Grain yield/ha(ton) } \\
\hline WW & 128.2 & $82.9(19)$ & $\begin{array}{l}168.1 \\
(1,5)\end{array}$ & 23 & 9.03 & $3.91(22)$ & $\begin{array}{l}15.25 \\
(8,5,6)\end{array}$ & 0.75 \\
\hline WSF & 91.4 & $31.8(22)$ & $\begin{array}{l}156.4 \\
(6,4)\end{array}$ & 13.3 & 5.8 & $1.39(22)$ & $\begin{array}{l}10.55 \\
(4,8.6)\end{array}$ & 0.63 \\
\hline WSG & 102.2 & $58.9(15)$ & $\begin{array}{l}179.7 \\
(8,6,4)\end{array}$ & 12.7 & 6.72 & $2.77(22)$ & $\begin{array}{l}13.45 \\
(8,6)\end{array}$ & 0.71 \\
\hline
\end{tabular}

Lowest and highest values are followed by genotype No. (Between brackets) 
Table 5. Mean grain yield/plant and mean grain yield/ha for each genotype under each watering treatment across two seasons

\begin{tabular}{|c|c|c|c|c|c|c|c|c|c|c|}
\hline \multirow[t]{2}{*}{ Genotype } & WW & WSF & $\mathrm{Ch} \%$ & WSG & $\mathrm{Ch} \%$ & WW & WSF & Ch\% & WSG & $\mathrm{Ch} \%$ \\
\hline & \multicolumn{5}{|c|}{ Grain yield/plant } & \multicolumn{5}{|c|}{ Grain yield/ha } \\
\hline 1 & 168.1 & 78.0 & 53.6 & 102.7 & 38.9 & 9.95 & 4.40 & 55.8 & 6.30 & 36.7 \\
\hline 2 & 131.7 & 73.3 & 44.3 & 92.0 & 30.1 & 8.51 & 3.79 & 55.5 & 5.51 & 35.2 \\
\hline 3 & 124.0 & 75.6 & 39.1 & 109.0 & 12.2 & 7.98 & 4.29 & 46.3 & 6.29 & 21.2 \\
\hline 4 & 151.6 & 147.9 & 2.5 & 132.5 & 12.6 & 9.56 & 8.35 & 12.7 & 6.36 & 33.5 \\
\hline 5 & 166.3 & 123.2 & 25.9 & 126.0 & 24.2 & 10.22 & 5.96 & 41.7 & 6.65 & 34.9 \\
\hline 6 & 150.4 & 156.4 & -4.0 & 168.7 & -12.2 & 10.05 & 8.14 & 19.1 & 8.38 & 16.6 \\
\hline 7 & 128.5 & 131.2 & -2.1 & 106.8 & 16.9 & 7.34 & 6.41 & 12.6 & 4.76 & 35.2 \\
\hline 8 & 150.4 & 137.6 & 8.5 & 179.7 & -19.5 & 12.11 & 8.21 & 32.2 & 10.67 & 11.9 \\
\hline 9 & 134.4 & 105.6 & 21.4 & 121.0 & 9.9 & 8.12 & 5.64 & 30.6 & 6.69 & 17.7 \\
\hline 10 & 134.3 & 98.9 & 26.4 & 117.7 & 12.3 & 8.32 & 5.31 & 36.2 & 6.43 & 22.8 \\
\hline 11 & 125.5 & 78.5 & 37.4 & 84.7 & 32.5 & 7.61 & 4.02 & 47.2 & 4.50 & 40.9 \\
\hline 12 & 119.4 & 91.0 & 23.8 & 111.5 & 6.6 & 7.79 & 5.12 & 34.2 & 6.09 & 21.8 \\
\hline 13 & 149.4 & 111.1 & 25.6 & 120.7 & 19.2 & 9.28 & 5.96 & 35.8 & 7.16 & 22.8 \\
\hline 14 & 133.6 & 89.7 & 32.9 & 81.9 & 38.7 & 5.65 & 4.15 & 26.5 & 3.86 & 31.7 \\
\hline 15 & 125.4 & 84.7 & 32.5 & 58.9 & 53.1 & 4.96 & 3.79 & 23.6 & 3.05 & 38.5 \\
\hline 16 & 118.6 & 56.2 & 52.6 & 81.9 & 30.9 & 4.30 & 2.84 & 33.9 & 4.12 & 4.1 \\
\hline 17 & 110.9 & 65.0 & 41.4 & 70.8 & 36.2 & 4.86 & 2.80 & 42.4 & 3.62 & 25.6 \\
\hline 18 & 110.5 & 74.2 & 32.9 & 85.8 & 22.4 & 5.37 & 3.22 & 40.1 & 4.54 & 15.4 \\
\hline 19 & 82.9 & 59.4 & 28.4 & 75.8 & 8.5 & 3.83 & 2.33 & 39.1 & 3.38 & 11.9 \\
\hline 20 & 106.6 & 79.7 & 25.2 & 91.4 & 14.3 & 4.64 & 3.00 & 35.4 & 3.63 & 21.9 \\
\hline 21 & 100.8 & 61.8 & 38.7 & 70.4 & 30.2 & 3.79 & 2.60 & 31.5 & 3.04 & 19.8 \\
\hline 22 & 96.9 & 31.8 & 67.2 & 58.9 & 39.3 & 3.10 & 1.11 & 64.2 & 2.19 & 29.4 \\
\hline Average & 128.2 & 91.4 & 28.7 & 102.2 & 20.3 & 7.15 & 4.61 & 35.5 & 5.33 & 25.5 \\
\hline Lowest & 82.9 & 31.8 & & 58.9 & & 3.10 & 1.11 & & 2.19 & \\
\hline Highest & 168.1 & 156.4 & & 179.7 & & 12.11 & 8.35 & & 10.6 & \\
\hline LSD. 05 & 23 & 13.3 & & 12.7 & & 0.6 & 0.5 & & 0.6 & \\
\hline
\end{tabular}

\subsection{Drought Tolerance Index}

Drought tolerance index (DTI) values of studied genotypes under the stressed environments WSF and WSG are presented in Table (7). According to our scale, when DTI is $\geq 1.0$, it indicates that genotype is tolerant $(T)$, if DTI is 1.0 , it indicates that genotype is moderately tolerant (MT) and if DTI is <1.0, it indicates that genotype is sensitive (S).

Based on DTI values, the 22 studied maize genotypes were grouped into three categories under water stress at flowering, namely tolerant (10 genotypes), moderately tolerant (two genotypes) and sensitive (10 genotypes) (Table 7). Under water stress conditions at grain filling, number of tolerant ( $T$ ), and sensitive (S) genotypes were 11 , and 11 , respectively.
The highest DTI under both the two stressed environments (WSF and WSG) was exhibited by the genotype No. 8 (P-3444). The $2^{\text {nd }}$ and $3^{\text {rd }}$ highest genotypes in DTI were SC-128 and Egaseed-77 under WSF and SC-128 and SC-10 under WSG. For productivity (grain yield/plant) under WSF, the genotype Egaseed-77 ranked $1^{\text {st }}$ , but P-3444 and SC-128 ranked $3^{\text {rd }}$. Under WSG, P-3444, SC-128 and SC-10 ranked $1^{\text {st }}, 2^{\text {nd }}$ and $3^{\text {rd }}$, for productivity as well as drought tolerance index.

On the contrary, the most drought sensitive genotypes were the open-pollinated populations Sweepstakes 5303, Golden Republic and Nebraska Midland under both water stress environments (WSF and WSG); their grain yield were the lowest. 
Table 6. The three highest and the three lowest genotypes for studied traits across seasons under drought stress at flowering (WSF) and at grain filling (WSG)

\begin{tabular}{|c|c|c|c|c|c|c|}
\hline \multirow[t]{2}{*}{ Water stress } & \multicolumn{3}{|c|}{ Highest } & \multicolumn{3}{|c|}{ Lowest } \\
\hline & \multicolumn{6}{|c|}{ Brace root whorls No. } \\
\hline WSF & Pop-45 & HT-1100 & 32D99 & Fine 1005 & SC-128 & Eg-77 \\
\hline \multirow[t]{2}{*}{ WSG } & 32D99 & $\mathrm{HT}-1100$ & TWC-360 & Eg-77 & P-3444 & $30 K 09$ \\
\hline & \multicolumn{6}{|c|}{ Brace root No. } \\
\hline WSF & 32D99 & TWC-352 & Pop-45 & Fine 1005 & Midland & Golden \\
\hline \multirow[t]{2}{*}{ WSG } & 32D99 & TWC-352 & HT-1100 & P-3444 & $\mathrm{Eg}-77$ & $30 K 09$ \\
\hline & \multicolumn{6}{|c|}{ Brace root angle (score) } \\
\hline WSF & Nebraska & Golden & Fine 1005 & SC-128 & HT-2066 & SC-166 \\
\hline \multirow{2}{*}{ WSG } & Nebraska & SC-10 & Golden & TWC-352 & Giza & TWC-324 \\
\hline & \multicolumn{6}{|c|}{ Brace root branching (score) } \\
\hline WSF & SC-128 & TWC-352 & SC-166 & Golden & Giza & Nebraska \\
\hline \multirow[t]{2}{*}{ WSG } & SC-166 & SC-128 & P-3444 & Nubaria & Wat- 11 & Golden \\
\hline & \multicolumn{6}{|c|}{ Crown root number (score) } \\
\hline WSF & SC-128 & P-3444 & HT-2066 & Eg-77 & Sweep & TWC-324 \\
\hline \multirow{2}{*}{ WSG } & Fine 1005 & HT-2031 & SC-128 & SC-166 & Midland & TWC-324 \\
\hline & \multicolumn{6}{|c|}{ Crown root angle (score) } \\
\hline WSF & Golden & 32D99 & Midland & TWC-360 & P-3444 & HT-2031 \\
\hline \multirow{2}{*}{ WSG } & 32D99 & Nebraska & Midland & P-3444 & HT-1100 & HT-2031 \\
\hline & \multicolumn{6}{|c|}{ Crown root branching (score) } \\
\hline WSF & SC-128 & P-3444 & TWC-352 & Fine 1005 & Eg-77 & TWC-324 \\
\hline \multirow[t]{2}{*}{ WSG } & P-3444 & HT-1100 & HT-2066 & Golden & 32D99 & TWC-324 \\
\hline & \multicolumn{6}{|c|}{ Crown root length $(\mathrm{cm})$} \\
\hline WSF & P-3444 & SC-166 & SC-10 & Pop-45 & HT-2066 & Midland \\
\hline \multirow[t]{2}{*}{ WSG } & Eg-77 & P-3444 & HT-1100 & Nubaria & Golden & Giza \\
\hline & \multicolumn{6}{|c|}{ Root circumference $(\mathrm{cm})$} \\
\hline WSF & HT-2066 & TWC-352 & TWC-352 & Nubaria & Midland & Golden \\
\hline \multirow[t]{2}{*}{ WSG } & P-3444 & $30 K 09$ & TWC-352 & Nebraska & Midland & Nubaria \\
\hline & \multicolumn{6}{|c|}{ Root dry weight (g) } \\
\hline WSF & SC-10 & Fine 1005 & SC-128 & Midland & TWC-324 & Golden \\
\hline \multirow[t]{2}{*}{ WSG } & P-3444 & HT-1100 & SC-128 & Nebraska & Midland & Nubaria \\
\hline & \multicolumn{6}{|c|}{ Grain yield/plant (g) } \\
\hline WSF & SC-128 & Eg-77 & P-3444 & Golden & Nebraska & Giza \\
\hline \multirow[t]{2}{*}{ WSG } & P-3444 & SC-128 & Eg-77 & Pop-45 & Golden & TWC-352 \\
\hline & \multicolumn{6}{|c|}{ Grain yield/ha } \\
\hline WSF & Eg-77 & $\mathrm{P}-3444$ & SC-128 & Pop-45 & Golden & Nebraska \\
\hline WSG & P-3444 & SC-128 & TWC-324 & Nebraska & TWC-352 & Golden \\
\hline
\end{tabular}

Table 7. Drought tolerance index (DTI) of studied genotypes across seasons under WSF and WSG

\begin{tabular}{llllll}
\hline Genotype & & DTI & Genotype & & DTI \\
\cline { 2 - 3 } & WSF & WSG & & WSF & WSG \\
\hline G1 & 1.30 & 1.60 & G12 & 1.20 & 1.20 \\
G2 & 1.00 & 1.20 & G13 & 1.70 & 1.70 \\
G3 & 1.00 & 1.30 & G14 & 0.70 & 0.60 \\
G4 & 2.40 & 1.60 & G15 & 0.60 & 0.40 \\
G5 & 1.80 & 1.80 & G16 & 0.40 & 0.50 \\
G6 & 2.50 & 2.20 & G17 & 0.40 & 0.50 \\
G7 & 1.40 & 0.90 & G18 & 0.50 & 0.60 \\
G8 & 3.00 & 3.40 & G19 & 0.30 & 0.30 \\
G9 & 1.40 & 1.40 & G20 & 0.40 & 0.40 \\
G10 & 1.30 & 1.40 & G21 & 0.30 & 0.30 \\
G11 & 0.90 & 0.90 & G22 & 0.10 & 0.20 \\
\hline
\end{tabular}




\subsection{Superiority of Drought Tolerant $(\mathrm{T})$ to Sensitive (S) Genotypes}

Based on grain yield/plant and drought tolerance index (DTI) the best three genotypes were the single cross hybrids P-3444, SC-128 and Egaseed-77 under WSF and P-3444, SC-128 and SC-10 under WSG, while the most drought sensitive and lowest yielding genotypes were the populations Sweepstakes, Golden Republic and Nebraska Midland under both water stress environments (WSF and WSG). Data averaged for each of the two groups ( $T$ and $S$ ) under WSF and under WSG indicated that GYPP of drought tolerant $(T)$ was greater than that of the sensitive (S) genotypes by 189.0and 131.3\% under drought at flowering (WSF) and grain filling (WSG), respectively (Table 8).

Significant superiority of drought tolerant (T) over sensitive (S) genotypes in GYPP under drought at flowering and grain filling was associated with significant superiority in higher $\mathrm{CN}$ (76.7 and 45.2\%), CB (42.6 and 84.4\%), higher CRL (11.3 and $25.4 \%$ ), higher $\mathrm{RC}(25.4$ and $23.6 \%)$ and higher RDW (86.7 and 126.3\%), respectively.

\subsection{Correlations among Drought Tolerance Index and Root Traits}

Drought tolerance index (DTI) showed a strong, significant $(p \leq 0.01)$ and positive correlation with grain yield/plant $\left(r=0.912^{* *}\right.$ and $\left.0.941^{* *}\right)$ under WSF and WSG conditions, respectively (Table 9). DTI was significantly and positively correlated with crown root length $\left(r=0.693^{* *}\right.$ and $\left.0.561^{* *}\right)$, root circumference $\left(0.440^{*}\right.$ and $\left.0.499^{*}\right)$, root dry weight $\left(r=0.410^{*}\right.$ and $\left.0.592^{* *}\right)$ under WSF and WSG conditions, respectively. Moreover, DTI had a significant and positive correlation coefficient with brace root branching $\left(0.506^{*}\right)$ and crown root branching $\left(0.489^{*}\right)$ under WSG and with Crown root branching (0.469) under WSF. On the contrary, DTI had a significant and negative correlation coefficient with brace root whorls; BW $\left(-0.598^{\star *}\right)$.

\subsection{Correlations among Grain Yield and Root Traits}

Estimates of rank correlation coefficients among GYPP and selected root traits across two seasons are presented in Table (10). Under WW, GYPP had a significant $(p \leq 0.01)$ and positive association with the root dry weight (RDW) (0.42), root circumference (RC) (0.43), crown root length (0.26), crown root branching (CB) (0.27), number of crown roots $(C N)(0.23)$ and brace root branching (BB) (0.34). Under WSF, GYPP had significant $(P \leq 0.01)$ and positive correlation with each of RC $(r=0.33)$ and $C N$ $(r=0.27)$. Under WSG, GYPP was significantly and positively correlated ( $p \leq 0.01$ or $p \leq 0.05$ ) with CRL ( $r=0.33)$, CB ( $r=0.25)$, RDW ( $r=0.23)$, BB $(r=0.18)$ and $R C(r=0.17)$.

\subsection{Grouping Genotypes}

\subsubsection{Based on drought tolerance and grain yield}

Mean grain yield/ha of studied genotypes under water stress at flowering (WSF) and grain filling (WSG), was plotted against drought tolerance index of the same genotypes under WSF and WSG; respectively (Fig. 2), which made it possible to distinguish between four groups, namely tolerant and high- yielding, tolerant and low-yielding, sensitive and high-yielding and sensitive and low-yielding according to Sattelmacher et al. [25], Worku et al. [26] and AlNaggar et al. [27,28].

Table 8. Superiority (Sup.\%) of the three most tolerant (T) to the three most sensitive (S) genotypes for selected traits under WSF and WSG across two seasons

\begin{tabular}{|c|c|c|c|c|c|c|}
\hline \multirow[t]{2}{*}{ Trait } & \multicolumn{3}{|c|}{ WSF } & \multicolumn{3}{|c|}{ WSG } \\
\hline & $\mathbf{S}$ & $\mathbf{T}$ & Sup. $\%$ & $\mathbf{S}$ & $\mathbf{T}$ & Sup. $\%$ \\
\hline Root dry weight & 10.70 & 20.10 & $86.7^{*}$ & 14.60 & 33.10 & $126.3^{* *}$ \\
\hline Crown root number & 2.40 & 4.20 & $76.7^{* *}$ & 2.30 & 3.40 & $45.2^{*}$ \\
\hline Crown root branching & 3.80 & 5.40 & $42.6^{*}$ & 2.50 & 4.60 & $84.4^{* *}$ \\
\hline Crown root length & 22.90 & 25.60 & $11.3^{*}$ & 18.60 & 23.30 & $25.4^{*}$ \\
\hline Root circumference & 28.40 & 35.60 & $25.4^{\star *}$ & 26.40 & 32.60 & $23.6^{*}$ \\
\hline Grain yield/plant & 51.00 & 147.30 & $189.0^{* *}$ & 68.30 & 158.10 & $131.3^{* *}$ \\
\hline
\end{tabular}


Table 9. Correlation coefficients between DTI and selected studied traits under water stress at flowering (WSF) and at grain filling (WSG) across seasons

\begin{tabular}{lll}
\hline Trait & WSF & WSG \\
\hline Crown root number & $0.469^{*}$ & 0.320 \\
Crown root branching & 0.381 & $0.489^{*}$ \\
Crown root length & $0.693^{* *}$ & $0.561^{* \pi}$ \\
Brace root whorls number & $-0.598^{* *}$ & -0.288 \\
Brace root Branching & 0.169 & $0.506^{*}$ \\
Root circumference & $0.440^{*}$ & $0.499^{*}$ \\
Root dry weight & $0.410^{*}$ & $0.592^{* \pi}$ \\
Grain yield/plant & $0.912^{* \pi}$ & $0.941^{* \pi}$ \\
\hline \multicolumn{1}{c}{${ }^{*}$ and ${ }^{* *}$ indicate significance at 0.05 and 0.01 probability levels, respectively }
\end{tabular}

Table 10. Correlation coefficients between grain yield/plant and selected root traits of maize under WW, WSF and WSG across two seasons

\begin{tabular}{llll}
\hline Trait & WW & WSF & WSG \\
\hline Branching density of brace roots (BW) & $0.34^{* *}$ & 0.13 & $0.18^{*}$ \\
Number of crown roots (CN) & $0.23^{* *}$ & $0.27^{* *}$ & $0.21^{* *}$ \\
Branching density of crown roots (CB) & $0.27^{* *}$ & 0.08 & $0.25^{* *}$ \\
Crown root length (CRL) & $0.26^{* *}$ & -0.03 & $0.33^{* *}$ \\
Root circumference (RC) & $0.43^{* *}$ & $0.33^{* *}$ & $0.17^{*}$ \\
Roots dry weight (RDW) & $0.42^{* *}$ & 0.13 & $0.23^{* *}$ \\
\hline
\end{tabular}

${ }^{*}$ and ${ }^{* *}$ indicate significance at 0.05 and 0.01 probability levels, respectively, $W W=$ Well watering, $W S F=W a t e r$ stress at flowering, WSG $=$ Water stress at grain filling
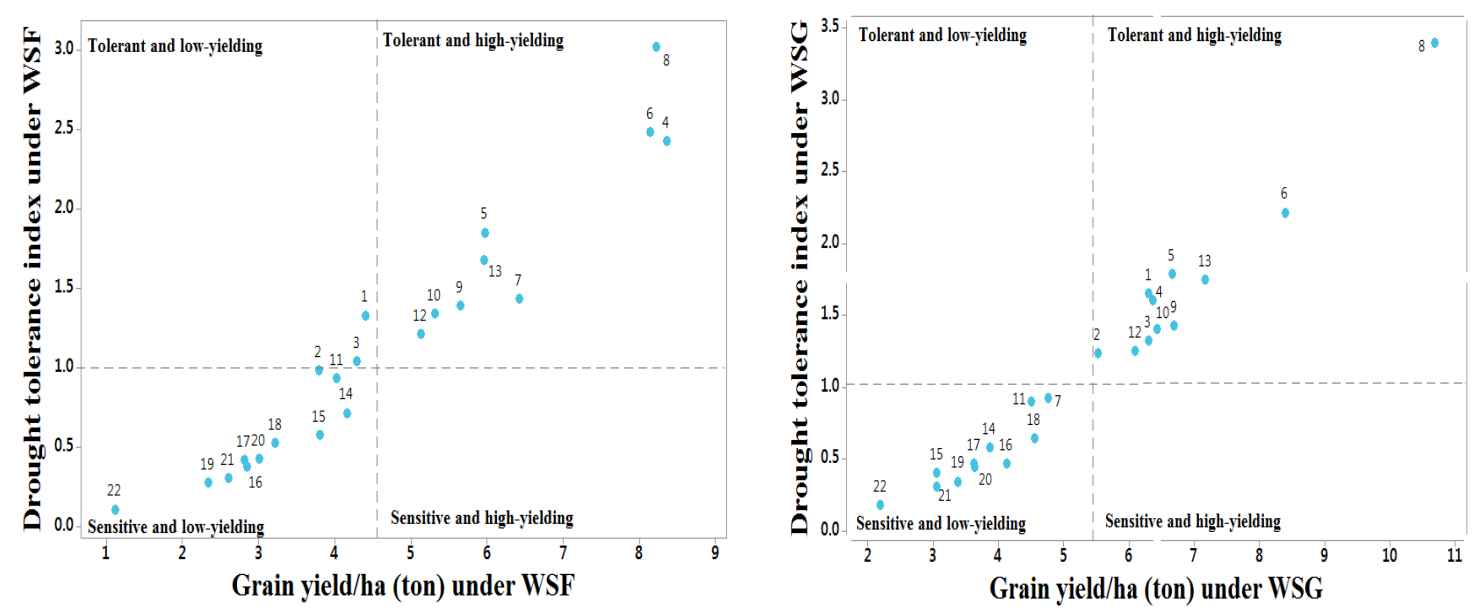

Fig. 2. Relationships between drought tolerance index (DTI) and means of GYPH of genotypes (from No.1 to No.22) under water stress at flowering (WSF) and grain filling (WSG) combined across seasons. Broken lines represent mean grain yield/ha and DTI

Under water stress at flowering (WSF), the genotypes No 8 followed by No. 4, 6, 5, 7, 13, 9, 10 and 12 were classified as the drought tolerant and high yielding genotypes, i.e. they could be considered as the most water stress tolerant and the most responsive genotypes to water stress at flowering in this study (Fig. 2). There was no genotype belonging to the group of sensitive and high yielding genotypes under WSF. The genotypes No. 1 and 3 occupied the group of tolerant and low yielding under WSF. The genotypes No 22, 19, 21, 16, 17, 20, 18, 15, 14, 11 and 2 were classified as water stress sensitive and low yielding and therefore could be considered sensitive and low yielding.

Under water stress at grain filling (WSG), the genotypes No. 8 followed by $6,13,5,1,4,9,10$, 3,12 and 2 were classified as drought tolerant and high yielding, they could be considered as 
the most water stress tolerant and the most responsive genotypes to water stress at grain filling in this study (Fig. 3). On the contrary, genotypes No. 22, 21, 15, 19, 20, 17, 16, 14, 18, 11 and 7 were classified as water stress sensitive and low yielding (Fig. 2).

According to Fageria and Baligar [29-31], genotypes belonging to the $1^{\text {st }}$ group "tolerant and high yielding" (above all) and $2^{\text {nd }}$ group "tolerant and low yielding" (to a lesser extent) (we did not have) appear to be the most desirable materials for breeding programs that deal with adaptation to water stress. It was observed that the genotypes No. 8, 6, 4, 13, 5, 9, 10 and 12 occupied the first group (E-R) under both WSF and WSG conditions; they had genes of high water efficiency; i.e. drought tolerance to both WSF and WSG stages and genes for high yield under well watering conditions.

Summarizing the above-mentioned classifications, it is apparent that the genotypes No. 8 (P-3444) followed by 6 (SC-128), 4 (Egaseed-77), 5 (SC-10), 13 (TWC-324), 7 (Hi Tec-2066), 9 (SC-166), 10 (P-32D99) and 12 (Watania 11) were the best genotypes that occupied the first group (best one) in both classifications; they are the most efficient, most drought tolerant, the highest yielder under WSF as well as WW. The genotypes No. 8 (P-3444) followed by 6 (SC-128), 13 (TWC-324), 5 (SC10), 1 (Hi Tec-2031), 4 (Egaseed-77), 9 (SC166), 10 (P-32D99), 3 (Fine 1005), 12 (Watania $11)$ and 2 (P-30K09) were the best genotypes that occupied the first group (best one) in both classifications; they are the most efficient, most drought tolerant, the highest yielder under WSG as well as WW.

It was observed that the genotypes No 8 ( $\mathrm{P}$ 3444) followed by 6 (SC-128), 4 (Egaseed-77), 5 (SC-10), 13 (TWC-324), 7 (Hi Tec-2066), 9 (SC166), 10 (P-32D99) and 12 (Watania 11) were the best in the first group for both stresses WSF and WSG; they are the most efficient, most drought tolerant and the highest yielders under WSF and WSG as well as WW. In accordance to these results, a previous study by Al-Naggar et al. [17], proved that the single cross hybrid SC-128 (genotype No. 6 in the present study) was the most water efficient (drought tolerant) under WSF and the most responsive to WW based on grain yield, ears/plant, kernels/ plant, $\mathrm{ASI}$ and leaf senescence.

\subsubsection{Based on drought tolerance and root traits}

Means of root traits of studied genotypes under water stress at flowering (WSF) and grain filling (WSG), were plotted against drought tolerance index (DTI) of the same genotypes under WSF and WSG; respectively (Fig. 3), which made it possible to distinguish between four groups, namely tolerant and high value of root trait, tolerant and low value of root trait, sensitive and high value of root trait and sensitive and low value of root trait. According to Fageria and Baligar [30], genotypes belonging to the $1^{\text {st }}$ group "tolerant and high value of root trait" (above all) appear to be the most desirable materials for breeding programs.

Fig. 3 indicates that the $1^{\text {st }}$ group "tolerant and high value of root trait" included the genotypes No. 10 and 12 under WSF, No. 10, 13, 6, 5 and 1 under WSG for number of whorls carrying brace roots, No. 10, 12, 1 and 5 under WSF, No. 10, $13,1,5$ and 6 under WSG for number of brace roots, No. 4, 13, 10, 12, 3 and 5 under WSF, No. $5,6,10,12,4$ and 3 under WSG for brace root angle, No. 6, 9, 10, 1 and 7 under WSF, No. 9, 6, 5,1 and 10 under WSG for brace root branching, No. 6, 8, 7, 1, 5, 3 and 2 under WSF, No. 3, 1, 6, 8,12 and 2 under WSG for number of crown roots, No. 10, 13, 12 and 5 under WSF, No. 10, $6,12,5$ and 2 under WSG for crown root angle, No. 6, 8, 9, 1, 7 and 5 under WSF, No. 8, 6, 1, 9, 4,3 and 12 under WSG for crown root branching, No. 8, 4, 5, 6, 9, 12, 1, 10 and 2 under WSF, No. $8,4,5,13,9,2,3,10$ and 12 under WSG for crown root length, No. 7, 6, 8, 5, 1, 10, 12, 2 and 3 under WSF, No. 8, 2, 1, 3, 13 and 5 under WSG for root circumference and No. 5, 6, 8, 10, 7, 1, 12, 3 and 2 under WSF, No. 8, 6, 1, 5, 2 and 12 under WSG for root dry weight.

\subsection{Mechanisms of Drought Tolerance of the Most Tolerant and High-yielding Genotypes}

The above-mentioned results (Figs. 2 and 3 ) helped us to identify the root traits that characterize the most drought tolerant and highyielding genotypes, in descending order, as follows:

1. Genotype No. 8 (SC-P-3444): Five traits (high $\mathrm{CN}, \mathrm{CB}$, large $\mathrm{RC}$, long $\mathrm{CRL}$ and heavy RDW) under both WSF and WSG.

2. Genotype No. 6 (SC-128): Four traits (high $\mathrm{CN}, \mathrm{CB}, \mathrm{BB}$, large $\mathrm{RC}$ and heavy RDW)under both WSF and WSG. 
3. Genotype No. 4 (SC-Egaseed-77): Two traits (steep brace root; i.e. large BA and long CRL) under both WSF and WSG.

4. Genotype No. 5 (SC-10): Six traits (high CN $\mathrm{CB}, \mathrm{BA}, \mathrm{RC}$, long $\mathrm{CRL}$ and heavy RDW) under WSF and five traits (high BA, CA, large $\mathrm{RC}$, long $\mathrm{CRL}$ and heavy RDW) under WSG.

5. Genotype No. 13 (TWC-324): Two traits (steep brace root; i.e. large BA and long crown root (CRL) under WSF and two traits (large RC and long CRL) under WSG.

6. Genotype No. 9 (SC-166): Two traits (high $\mathrm{CB}$ and long crown root $\mathrm{CRL}$ ) under both WSF and WSG.

7. Genotype No. 10 (SC-P-32D99): Four traits (steep crown root; CA steep brace root; BA, long crown root; $\mathrm{CRL}$ and heavy root dry
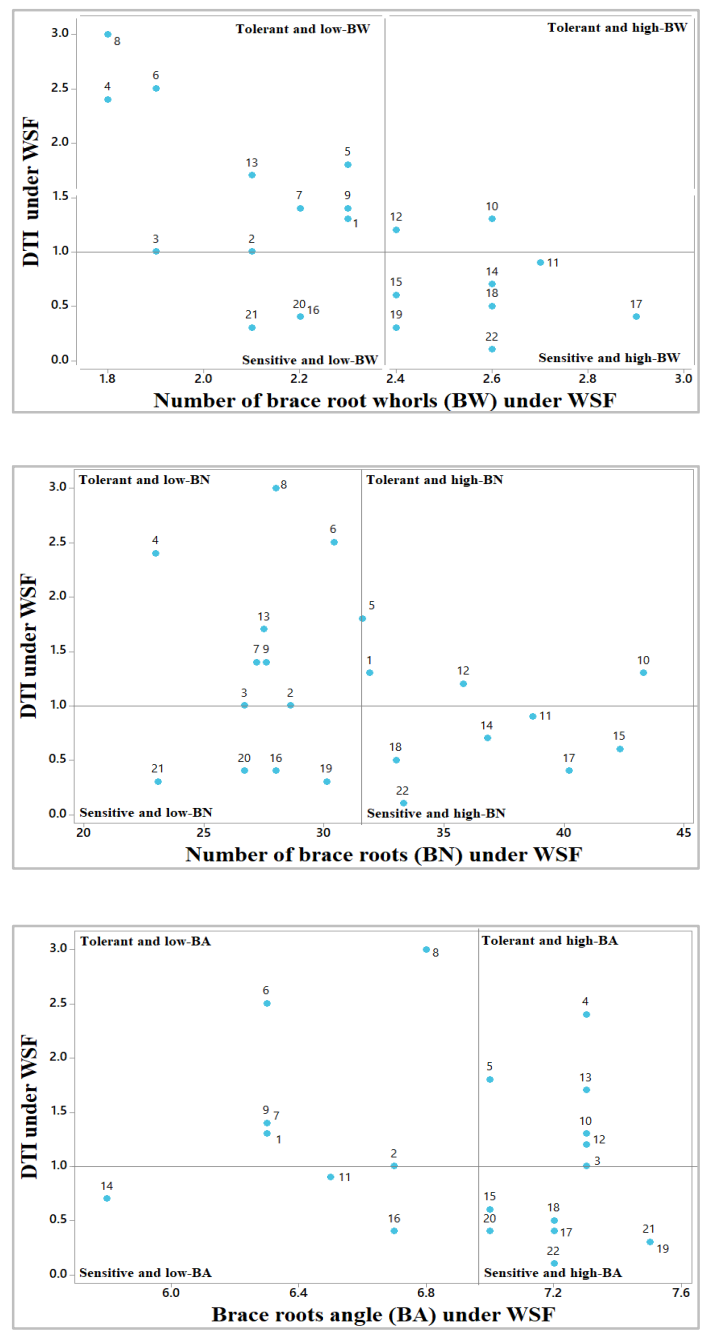

weight; RDW) under both WSF and WSG and one trait (heavy RDW) under WSF.

8. Genotype No. 12 (Watania TWC-11): Seven traits (BW, BN, BA, CA, CRL, RC and RDW) under WSF and six traits (BA, $\mathrm{CN}, \mathrm{CA}, \mathrm{CB}, \mathrm{CRL}$ and RDW) under WSG.

The present study suggested that further investigation should be conducted to determine the underlying root mechanisms contributing to the selection of water-efficient hybrids of maize. In a recent study [32], maize genotypes with less variation in root size, medium root size, medium broad root system and more inter-row root distribution help to reduce root-to-root competition and tend to have higher yield at high planting density.
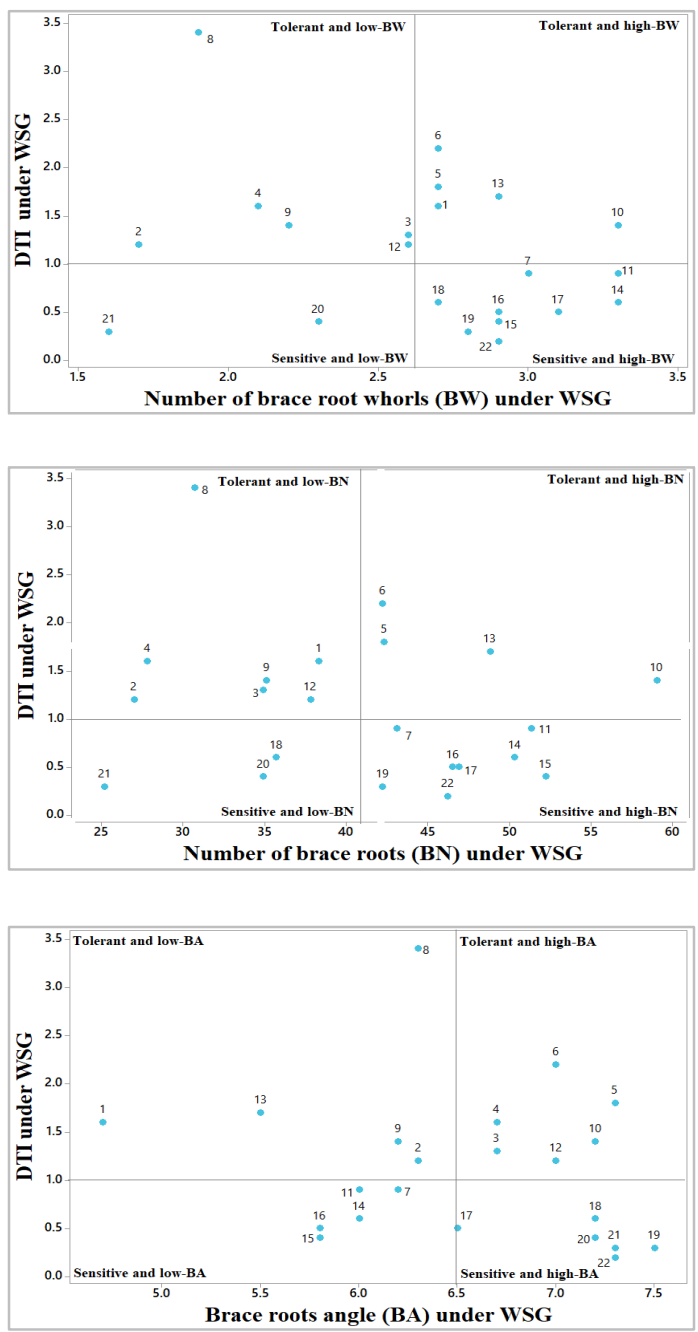

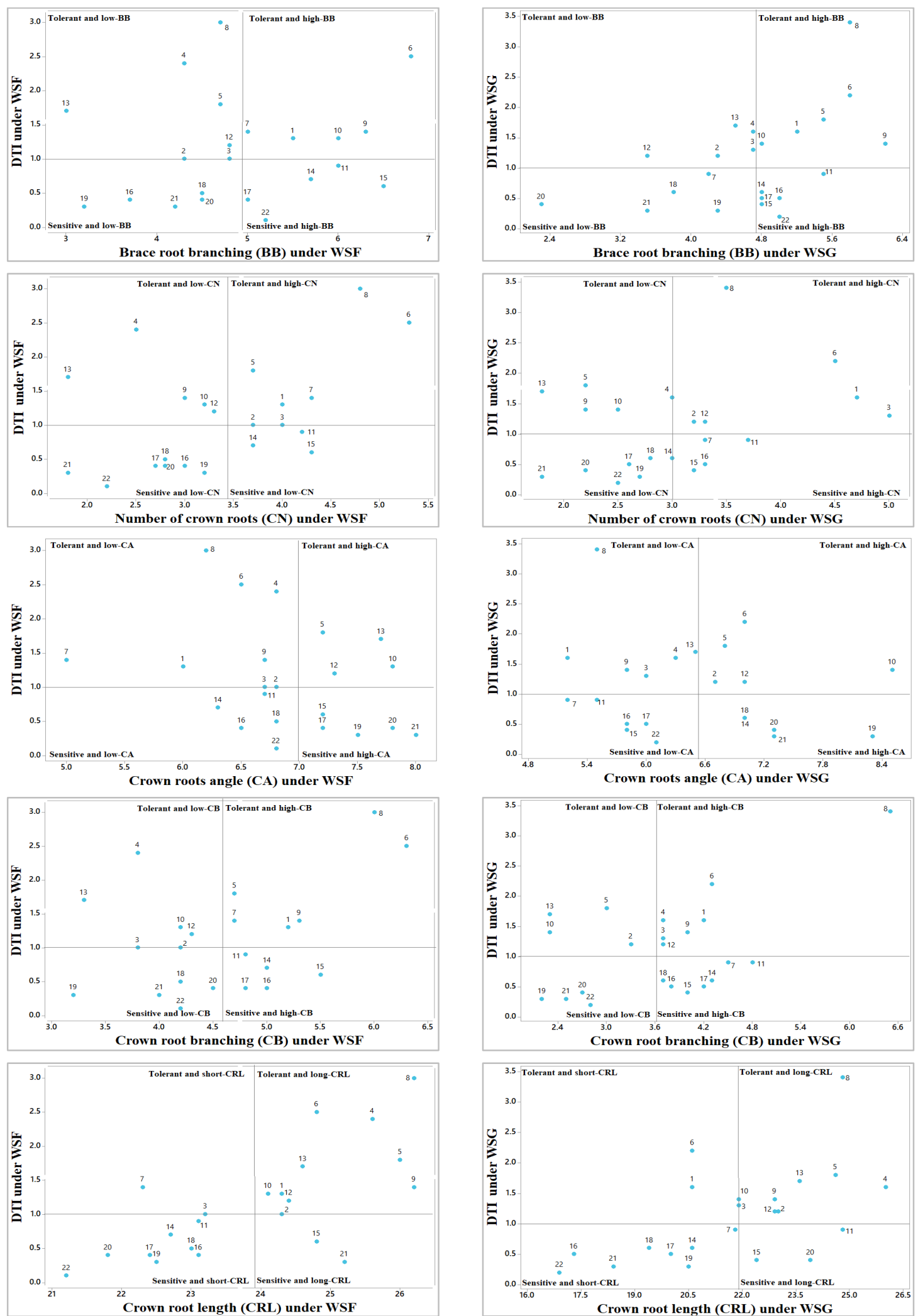

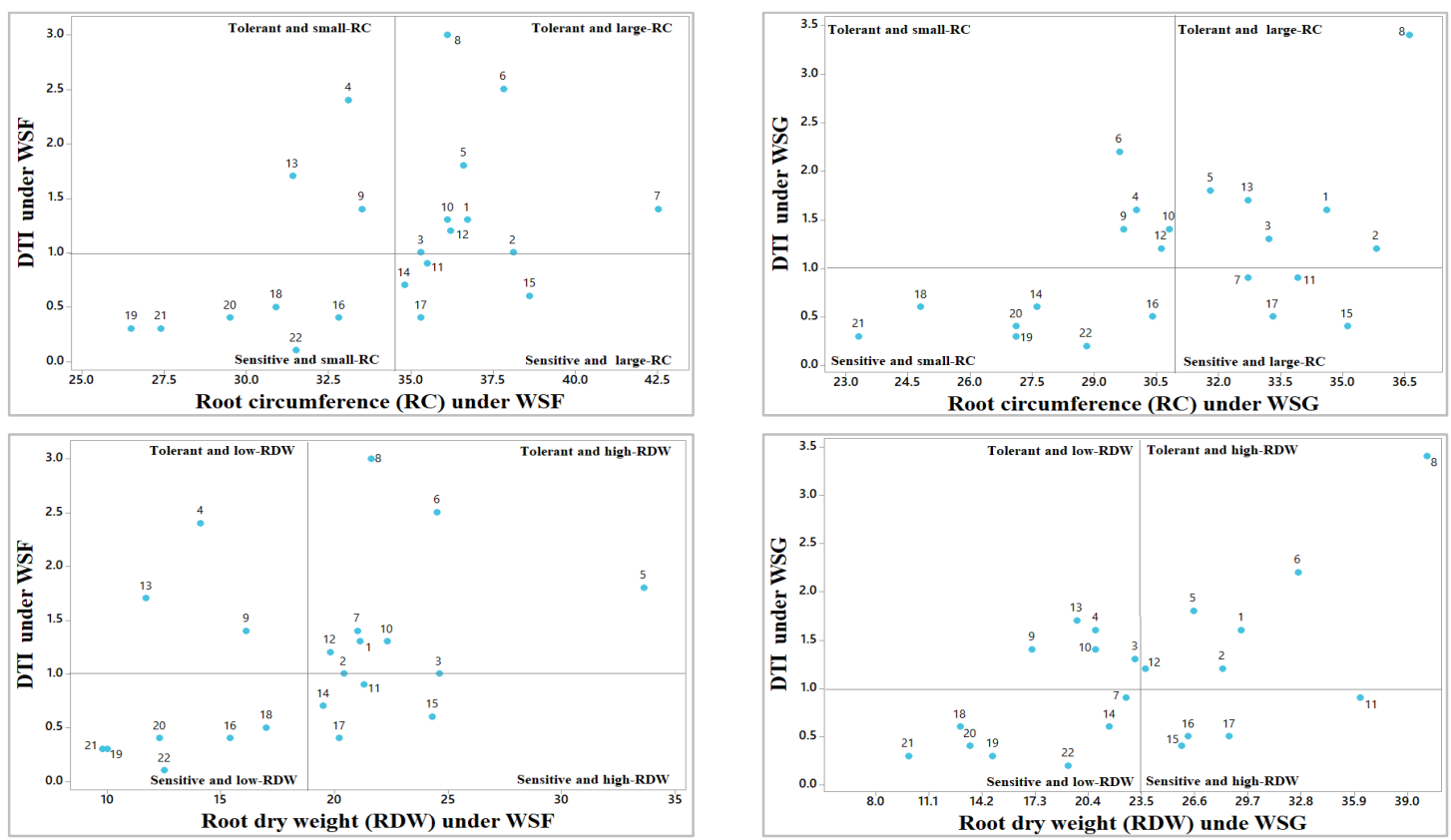

Fig. 3. Relationships between drought tolerance index (DTI) and means of number of whorls carrying brace roots, brace root branching, crown root number, crown root branching, root circumference, crown root length, and root dry weight, of genotypes (from No. 1 to No.22) under water stress at flowering (WSF) and grain filling (WSG) combined across seasons. Broken lines represent mean DTI and root trait.

\section{CONCLUSIONS}

Correlation analysis of the present study concluded that drought tolerance in maize had a strong and positive association with crown root length, root circumference and root dry weight under both WSF and WSG, a negative correlation with brace root whorls, and a positive correlation with crown root number under WSF and brace root branching and crown root branching under WSG. These root traits could be considered as putative mechanisms of drought tolerance. The present study suggested that further investigation should be conducted to determine the underlying plant mechanisms contributing to the selection of water-efficient hybrids of maize. The cultivars Pioneer-3444, SC-128, Egaseed-77, SC-10 and TWC-324 showed the most drought tolerance and the highest yielding in a descending order; each had a number of such drought tolerance mechanisms. These cultivars should be retested for drought tolerance and grain productivity under drought stress and could be offered to plant breeding programs for improving tolerance to drought and high grain yield.

\section{COMPETING INTERESTS}

Authors have declared that no competing interests exist.

\section{REFERENCES}

1. Bai LP, Sui FG, Ge TD, Sun ZH, Lu YY, Zhou GS. Effect of soil drought stress on leaf water status, membrane permeability and enzymatic antioxidant system of maize. Pedosphere. 2006;16:326-332.

2. Witt S, Galicia L, Lisec J, Cairns J, Tiessen A, Araus JL, Palacios-Rojasand N, Fernie ARR. Metabolic and phenotypic responses of greenhouse-grown maize hybrids to experimentally controlled drought stress. Mol. Plant. 2012;5:401-417.

3. Edmeades GO, Bolanos J, Hernandez M, Ballo S. Causes for silk delay in a low land tropical maize population. Crop Sci. 1993; 33:1029-1035.

4. Lynch JP. Root architecture and plant productivity. Plant Physiol. 1995;109:7-13.

5. Lynch JP. Roots of the second green revolution. Aust. J. Bot. 2007;55:493-512. 
6. Hund A, Reimer R, Messmer R. A consensus map of QTLs controlling the root length of maize. Plant and Soil. 2011; 344:143-158.

7. Rauf S, Sadaqat HA. Effect of osmotic adjustment on root length and dry matter partitioning in sunflower (Helianthus annuus L.) under drought stress. Acta Agric Scand, Section B, Soil \& Plant Sci. 2008;58(3):252-260.

8. Rauf S, Sadaqat HA, Ahmed R, Khan IA. Genetics of root characteristics in sunflower (Helianthus annuus L.) under contrasting water regimes. Ind. J. Plant Physiol. 2009;14:319-327.

9. King CA, Purcell LC, Brye KR. Differential wilting among soybean genotypes in response to water deficit. Crop Sci. 2009; 49:290-298.

10. Trachsel S, Kaeppler SM, Brown KM, Lynch JP. Shovelomics: High throughput phenotyping of maize (Zea mays L.) root architecture in the field. Plant Soil. 2011; 341:75-87.

11. Fageria NK. Maximizing crop yields. Dekker. New York. 1992;423.

12. Steel RGD, Torrie GH, Dickey DA. Principles and procedures of statistics: A biometrical approach. $3^{\text {rd }}$ ed. McGraw-Hill, New York, USA; 1997.

13. Singh $P$, Narayanan SS. Biometrical techniques in plant breeding. Kalayani Publishers, New Delhi, India; 2000.

14. Al-Naggar AMM, Abdalla AMA, Gohar AMA, Hafez EHM. Tolerance of 254 maize doubled haploid lines $\times$ tester crosses to drought at flowering and grain filling. J. Appl. Life Sci. Inter. 2016;9(4):1-18.

15. Al-Naggar AMM, Shafik MM, Elsheikh MO. Correlations and heritability for root architecture traits of maize under water stress at flowering and grain filling. Bioscience Research. 2018;15(4):45714583.

16. Al-Naggar AMM, Shabana $R$, Mahmoud AA, Abdel El-Azeem MEM, Shaboon SAM. Recurrent selection for drought tolerance improves maize productivity under low-N conditions. Egypt. J. Plant Breed. 2009; 13:53-70.

17. Al-Naggar AMM, Soliman SM, Hashimi MN. Tolerance to drought at flowering stage of 28 maize hybrids and populations. Egypt. J. Plant Breed. 2011;15(1):69-87.

18. Al-Naggar AMM, Atta MMM, Ahmed MA, Younis ASM. Influence of deficit irrigation at silking stage and genotype on maize
(Zea mays L.) agronomic and yield characters. J. Agric. and Ecol. Res. Inter. 2016b;7(4):1-16.

19. Al-Naggar AMM, Shabana R, Hassanein MS, Metwally AMA. Effects of genotype, plant density and their interaction on maize yield and traits related to plant density tolerance. Bioscience Research. 2017; 14(2):395-407.

20. Al-Naggar AMM, Shabana R, Hassanein MS, Elewa TA, Younis ASM, Metwally AMA. Secondary traits and selection environment of plant density tolerance in maize in breds and testcrosses. Journal of Advances in Biology \& Biotechnology. 2017;14(3):1-13.

21. Wright GC, Nageswara Rao RC. Groundnut water relations. In: Smartt J (Ed.) The groundnut crop: A scientific base for improvement. Chapman and Hall, London, UK. 1994;281-325.

22. Henry A, Gowda VRP, Torres RO. Variation in root system architecture and drought response in rice (Oryza sativa): phenotyping of the Oryza SNP panel in rainfed lowland fields. Field Crops Res. 2011;120:205-214.

23. Hund A, Trachsel S, Stamp P. Growth of axile and lateral roots of maize: I Development of a phenotyping platform. Plant and Soil. 2009;325(1):335-349.

24. Hund A. Genetic variation in the gravitropic response of maize roots to low temperatures. Plant Root. 2010;4:22-30.

25. Sattelmacher B, Horst WJ, Becker HC. Factors that contribute to genetic variation for nutrient efficiency of crop plants. Zeitschrift fur Planzenernährung und Bodenkunde. 1994;157:215-224.

26. Worku M, Banziger M, Erley GSA, Alpha DF, Diallo O, Horst WJ. Nitrogen uptake and utilization in contrasting nitrogen efficient tropical maize hybrids. Crop Sci. 2007;47:519-528.

27. Al-Naggar AMM, Shabana RA, Atta MMM, Al-Khalil TH. Maize response to elevated plant density combined with lowered $\mathrm{N}$ fertilizer rate is genotype-dependent. The Crop Journal. 2015;3(2):96-109.

28. Al-Naggar AMM, Shafik MM, Elsheikh MO. Influences of genotype and drought at flowering and grain filling on root architecture traits of Zea mays L. Asian Journal of Agricultural and Horticultural Research. 2018;2(4):1-14.

29. Fageria NK, Baligar VC. Screening crop genotypes for mineral stresses. In: 
Adaptation of Plants to Soil Stress, (Eds. Maranville J, Baligar W, Duncan VC, RR, Yohe JM), Nebraska-Lincoln Press, Inc, United states, NE. 1994;152-159.

30. Fageria NK, Baligar VC. Phosphorous-use efficiency by corn genotypes. J. Plant Nutr. 1997;20:1267-1277.

31. Fageria NK, Baligar VC. Integrated plant nutrient management for sustainable crop
production-An over. Inter. J. Trop. Agri. 1997;15:7-18.

32. Shao H, Dongfeng S, Wenjun S, Xiangben B, Yachao C, Wei R, Fanjun C, Guohua M. Genotypic difference in the plasticity of root system architecture of field-grown maize in response to plant density. Plant Soil. 2019; 1-17.

DOI: doi.org/10.1007/s11104-019-03964-8

(c) 2019 Al-Naggar et al.; This is an Open Access article distributed under the terms of the Creative Commons Attribution License (http://creativecommons.org/licenses/by/4.0), which permits unrestricted use, distribution, and reproduction in any medium, provided the original work is properly cited.

Peer-review history:

The peer review history for this paper can be accessed here: http://www. sdiarticle3.com/review-history/49679 